DOI: 10.15587/2706-5448.2022.251505

Article type «Reports on Research Projects»

\section{Oleksandr Gryshchuk, Anatoliy Petryk, Yaroslav Yerko}

\title{
DEVELOPMENT OF METHODS FOR FORMATION OF INFRASTRUCTURE OF TRANSPORT UNITS FOR MAINTENANCE OF TRANSIT AND EXPORT FREIGHT FLOWS
}

Coordinated development of foreign economic relations and increase in international trade are the main factors of successful socio-economic growth of the state. And in order to ensure the competitiveness of domestic products on the world market, the primary factors are the intensification of innovative activities of production structures and the optimal use of national resources. The object of research is the processes of forming the infrastructure of customs and logistics systems, taking into account the assessment of the competitiveness of transport services. These results depend on the resource provision of the processes of servicing import-export and transit cargo flows.

In the course of the research carried out in the work, the following methods were used: the method of factor analysis of the use of transport systems infrastructure; mathematical apparatus of decision theory; methods of simulation modeling of development of integration processes for calculations of integrated indicators. Regularities of the organization of foreign trade deliveries of transit and export cargoes as a basis for creation of effective system of management of customs and logistic processes are defined and the methodology of qualitative transport service on an example of grain cargo flows is developed. A method of forming the infrastructure of transport hubs for servicing cargo flows on the basis of economic analysis of the development of integration processes in the form of interaction of structural elements of production systems and their relationships. The performed work provided an opportunity to develop a model of intensive use of existing and promising infrastructure of transport systems and to conduct multivariate calculations to determine the amount of resources for the organization of foreign trade supplies on the basis of demand.

The study is aimed at gaining new knowledge about the patterns of improving the efficiency of customs and logistics services for foreign trade flows in international production structures. In the course of the research the approbation of the developed methodology for the formation and optimization of the infrastructure of transport hubs in the management systems of international production processes was carried out.

Keywords: transport infrastructure, customs and logistics services, transport and production systems, integration processes, transport nodes, technological characteristics.

\section{How to cite}

Gryshchuk, O., Petryk, A., Yerko, Y. (2022). Development of methods for formation of infrastructure of transport units for maintenance of transit and export freight flows. Technology Audit and Production Reserves, 1 (2 (63)), 26-30. doi: http://doi.org/10.15587/2706-5448.2022.251505

\section{Introduction}

Global trends in the rapid development of trade relations are based on the principles of economic integration between individual countries and the relocation of production processes in international production structures. Due to the economic growth of the world economy, according to industry experts, the trends in the development of integration processes recorded in the recent period will be maintained for a long time. Increasing the volume of production and sales of industrial goods and food products requires the creation of new and intensive use of existing infrastructure of production units. Therefore, the develop- ment of competitive transport and technological systems for servicing foreign trade flows with minimal logistics costs is one of the main tasks of relevant government and commercial structures [1,2].

Given the peculiarities of the implementation and growth of export traffic on the example of grain cargo, special attention should be paid to the organization of foreign trade supplies of these products through sea trade ports. Existing trends to increase exports and transit of these agro-industrial products through the country outlined scientific prospects for developing technological and structural principles to improve the transportation of these goods under intensive use of existing infrastructure of economic entities [3, 4]. 
The transport system of export orientation is characterized by a significant degree of diversification and a high level of interaction of the main modes of transport. With a clear organization of trade, optimal distribution of material and financial resources and coordinated work of economic structures, it becomes possible to carry out large-scale foreign trade operations with import and export cargo. And the introduction of innovative digital technologies will allow the use of transport in a more efficient and rational development scenario [5, 6].

The introduction of integration processes necessitates the formation of infrastructural support of transport and technological systems for servicing transit and export grain cargo flows. Therefore, for high-quality logistics services of foreign trade flows in transport hubs, a suitable set of measures may be the formation of appropriate production infrastructure based on the use of the basic principles of the theory of optimization of material resources.

Thus, the object of research in the work are the processes of forming the infrastructure of customs and logistics systems of export orientation, taking into account the assessment of the competitiveness of transport services. And the aim of research is to develop and use practical methods of forming the production infrastructure in transport hubs on the example of servicing grain cargo flows in international traffic [7, 8].

\section{Research methodology}

Improving the organizational principles of management of the transportation process of grain cargo and customs and logistics support of these cargo flows is considered on the example of the operation of a specialized terminal in a sea trade port [2, 9]. The use of the methodology of formation of production infrastructure for logistics services of grain cargo flows involves multivariate calculations to determine the numerical values of the main technical and technological indicators. The criterion for choosing a rational set of structural elements in transport and logistics systems adopted generalized logistics costs. And modeling the process of servicing grain cargo flows in logistics units takes into account the peculiarities of the interaction of rolling stock of different modes of transport, the intensity of existing infrastructure, opportunities and prospects for the use of production facilities and elevators [10, 11].

Application of the offered technique and carrying out of the corresponding calculations will allow receiving the corresponding recommendations for definition of optimum technological characteristics of infrastructural system elements. Taking into account the peculiarities of the functioning of transport hubs makes it possible to purposefully find ways to improve the efficiency of the entire transport system. And the practical value of the methodology is to assess the impact of random nature of individual factors on the performance of the transportation process.

The growth of export volumes of grain cargo flows is one of the main trends in international transportation, which takes place on the basis of economic integration between individual countries. However, the transport flows of these cargoes in international traffic are distributed mainly by sea routes using mixed traffic. The method of optimization of generalized logistics costs is considered under the condition of processing the export batch of grain cargo on the example of Odesa Commercial Sea Port (Ukraine).
The optimization problem of material resource allocation was solved in the MathCAD environment using known methods of economic and mathematical modeling. The algorithm of realization of the developed mathematical model assumes application of the basic theoretical positions of matrix algebra. To this end, as a result of the generalization of a large number of possible schemes of consolidation and movement of grain cargo flows in the direction of «linear elevator - ship» it becomes possible to identify eight main options for the use of transport infrastructure. Then the number of columns in the matrix $A$ corresponds to the number of options for servicing the export batch of goods, and the horizontal matrix is the numerical values of the technological characteristics of individual infrastructure elements in each of the selected schemes.

In this case, the daily intensity of use of the production infrastructure of transport and logistics systems under separate schemes for creating and loading a consolidated batch of grain cargo with a total volume of 40 thousand tons for 5 days is characterized by a matrix of coefficients:

$$
A:=\left(\begin{array}{cccccccc}
10 & 10 & 10 & 0 & 0 & 0 & 0 & 0 \\
0 & 0 & 0 & 40 & 40 & 40 & 0 & 0 \\
0 & 0 & 0 & 0 & 0 & 0 & 40 & 40 \\
31 & 31 & 31 & 123 & 123 & 0 & 0 & 0 \\
0 & 0 & 0 & 0 & 0 & 500 & 500 & 125 \\
0 & 0 & 0 & 0 & 0 & 500 & 500 & 0 \\
0 & 0 & 40 & 0 & 0 & 0 & 0 & 40 \\
123 & 0 & 0 & 123 & 0 & 0 & 0 & 0 \\
0 & 8 & 8 & 0 & 8 & 8 & 8 & 8
\end{array}\right) .
$$

Peculiarities of using the production infrastructure of transport and logistics systems within the activity of the Odesa Commercial Sea Port are characterized by the vector of limitations of material and financial resources (matrix B). Possible numerical values of infrastructure characteristics for the consolidated consignment of grain cargoes take into account the allowable time parameters of the future accumulation of these goods and possible risks and financial losses due to non-fulfillment of contractual obligations. For example, during the process of export movement of these goods, this possibility was taken into account by the limit of 8 thousand tons/day for the total daily capacity of linear elevators for grain shipment (the upper value of the matrix $B$ ).

The design productivity of the grain terminal for processing railway cars (the fourth value of the matrix $B$ ) is of great importance in the process of rational organization of logistic service of freight flows in transport nodes. This integrated indicator of 95 wagons/day takes into account the service requirements not only from linear elevators, but also pre-loaded transport units, which temporarily store part of the export batch of grain (the fourth value of the matrix $B$ ).

The capacity of the port elevator of 15 thousand tons also has a significant impact on the intensity of infrastructure use in the existing customs and logistics systems. Systematic use of this business entity (the seventh value of the matrix $B$ ) significantly increases the stability of the transport and technological process, and limiting the capacity of customs warehouses (terminals) is dictated by the need to use appropriate elevator and storage facilities for processing industry. 
In this case, the vector of restrictions on material resources for the maintenance of grain cargo flow for individual transport schemes is characterized as follows:

$$
B:=\left(\begin{array}{c}
8 \\
30 \\
4 \\
95 \\
55 \\
40 \\
15 \\
50 \\
5
\end{array}\right) .
$$

The total cost of logistics services for the maintenance of grain cargo flows in the export service is differentiated by such components as:

- services of grain-receiving enterprises;

- direct transportation of goods;

- services of customs warehouses and grain terminals;

- cost of reloading operations in the transport node;

- freight toll of the sea trade port.

The total cost of basic and additional services ( $m a-$ trix $C$ ) related to production operations at elevator and warehousing enterprises for certain technological schemes consists of receiving grain cargo, storing them for the time specified in the contract and other operations specified in the technical conditions of service, EUR/ton:

$$
C:=\left(\begin{array}{l}
41.14 \\
39.32 \\
30.69 \\
36.65 \\
34.98 \\
34.71 \\
19.26 \\
23.26
\end{array}\right) .
$$

The total cost of logistics services $C$ is an integrated indicator calculated by the main types of costs. However, in the specified value $C$ there are no additional costs associated with freight forwarding, reloading, sealing of railway cars, etc.

As a result of solving the system of equations in the MathCAD environment, it became possible to determine:

- generalized cost of logistics services:

$$
F(x)=\sum_{j=1}^{n} c_{j} x_{j}
$$

- volumes of grain cargo transportation under a separate transport scheme $X_{\text {opt }}=\operatorname{Minimize}(F, X)$;

- optimal plan for the use of transport infrastructure $W^{T}=A X_{\text {opt }}$

Differentiated analysis of multivariate calculations to determine the numerical values of the parameters of infrastructure for the maintenance of grain cargo flows allows determining the technical and operational parameters of components and analyzing the trend of numerical values of individual elements under the influence of perturbing factors.

These theoretical prerequisites for improving the customs and logistics services of export and transit grain cargo flows in transport hubs make it possible to optimize logistics costs in the service of these goods.
In the case of forming the infrastructure of customs and logistics systems in transport hubs, the research task is to determine the volume of transportation $x_{j}$ according to separate schemes $P_{j}, j=1, \ldots, n$, when the generalized logistical cost of moving a unit of grain production is minimized. Therefore, for the conditions of rational organization of foreign trade supplies of these goods, such a task is formally reduced to finding a vector $x=\left(x_{1}, \ldots, x_{n}\right) \in E^{n}$, which minimizes the linear function:

$$
F(x)=\sum_{j=1}^{n} c_{j} x_{j} \rightarrow \min .
$$

Given the use of the existing customs and logistics infrastructure of the transport hub, the system of linear equations must meet the production constraints as follows:

$$
\begin{aligned}
& \left\{\begin{array}{l}
a_{11} x_{1}+a_{12} x_{2}+\ldots+a_{1 n} x_{n} \leq b_{1} \\
a_{21} x_{1}+a_{22} x_{2}+\ldots+a_{2 n} x_{n} \leq b_{2} \\
\cdots \ldots \ldots \ldots \ldots \ldots \ldots \ldots \ldots \ldots \ldots \ldots \ldots \ldots \ldots \ldots \\
a_{m 1} x_{1}+a_{m 2} x_{2}+\ldots+a_{m n} x_{n} \leq b_{m}
\end{array}\right\}, \\
& x_{1} \geq 0, \quad x_{2} \geq 0, \quad x_{n} \geq 0 .
\end{aligned}
$$

The vector $x$, which characterizes the conditions for solving mathematical expressions (2) and (3), is considered an acceptable plan for the use of customs and logistics infrastructure, and their set determines the limited area $D$ of the problem. The objective function $F(x)$ for $x^{*} \in D$ provides a minimum of total costs for the consolidation and maintenance of grain traffic in the transport hub. In this case, the results of calculations for $F\left(x^{*}\right)$ are considered the optimal solution of the objective function, and the obtained results of the condition $X_{\text {opt }}=\operatorname{Minimize}(F, X)$ - rational plan for the formation of the infrastructure of the customs and logistics system.

\section{Research results and discussion}

In the service of transit and export grain cargo flows in the process of forming the infrastructure network of transport systems, the points of preliminary accumulation of cargo are of great importance. For this purpose, the influence of the capacity of customs-licensed warehouses $M$ on the numerical value of generalized logistics costs $B$ under the conditions of compliance with a certain level of productivity of ship loading mechanisms $Z$ of the grain terminal was analyzed (Fig. 1).

According to calculations, the increase in the volume of pre-storage capacity of grain for the maintenance of export and transit cargo flows has a positive effect on reducing overall logistics costs. Changing the indicator $M$ from 5 thousand tons to 30 thousand tons reduces the generalized costs $B$ from $7.1 \%$ under the condition $Z=1$ thousand tons/day to $6.8 \%$ under the condition $Z=5$ thousand tons/day. These results are explained by the decrease in the share of terminal loading volumes of the vessel under the condition of their preliminary accumulation in storage facilities and the corresponding increase in the volume of grain loaded under the direct option. In this case, the reduction in $B$ is largely due to the lack of costs associated with the use of rail cars and storage of goods in them. And the involvement in the transport and technological process of customs terminals located in the immediate vicinity of the railway junction reduces the queues waiting for service cars. 


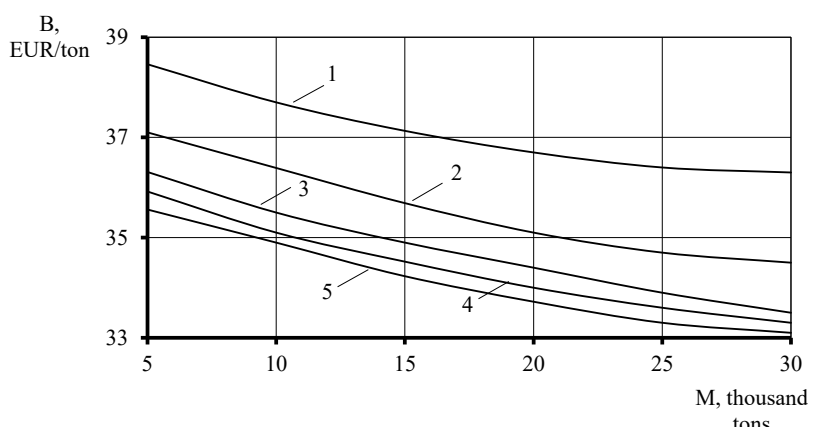

tons

Fig. 1. Dependence of the generalized cost of logistics services for export batch service ( $P=40$ thousand tons) of grain cargo on the change in capacity of the customs terminal provided the productivity

of ship loading mechanisms of the grain terminal, tons/day:

1 - 1000; 2 - 2000; 3 - 3000; 4 - 4000; 5 - 5000

Increasing the productivity of ship loading mechanisms of grain terminal $Z$ also has a positive effect on reducing generalized logistics costs $B$. Thus, changing the technological parameter $Z$ from 1 thousand tons/day to 5 thousand tons/day leads to a decrease in $B$ within $7.0-6.7 \%$ provided that the transport system is provided with pre-storage capacities of grain in the range $M=5-30$ thousand tons.

The reduction of generalized logistics costs $B$ is also due to the possibility of intensive use of port elevator $H$, and, consequently, an increase in transshipments operations using ship loading mechanisms and a corresponding reduction in the volume of transport services of grain cargo flows of port elevators. And the need to perform transshipment operations on the direct option is eliminated while maintaining the productivity of ship loaders at the level of $Z$ for $M=3$ thousand tons/day provided the capacity of the customs terminal $M=25$ thousand tons, for $Z=4$ thousand tons/day provided $M=20$ thousand tons and for $Z=5$ thousand tons/day - provided $M=15$ thousand tons. In addition, with the increase in the productivity of ship loading machines $Z$ to 4 thousand tons/day, it becomes possible to partially use watercraft, the use of which is somewhat more economical compared to the direct method of transshipment operations.

In the general strategy of development of port complexes it is important to determine the optimal technical and technological characteristics of each of the components of the transport hub in the logistics port network. The key activities of specialized terminals, subject to their cooperation within the transport system with other production structures are related to the processing of grain cargo flows. These infrastructure elements to perform their functions must be equipped with adequate capacity and occupy a key position in the transport system. Transshipment of cargo in individual nodes should be considered as a defining element of the entire transport network, as the work of other involved nodes will depend on the volume of cargo work performed in a specialized terminal and its position in the market of logistics services.

An independent factor influencing the numerical value of generalized logistics costs $B$ in the system of export and transit transportation of grain cargo is the capacity $H$ of the port elevator. The presence of such an element in the production system allows by abandoning the corresponding volumes of grain products to abandon the use of intermediate storage points (customs terminals). As well as significantly reduce downtime of rolling stock in anticipation of unloading operations and increase the reliability of maintenance of vessels in transport hubs. Such an impact can be especially important if a strong export consignment of grain cargo is moved. Therefore, to optimize logistics costs, the influence of the capacity of the port elevator $H$ on the numerical value of indicator $\mathrm{B}$ was determined, provided that a certain level of productivity of the grain terminal $D$ for processing railway cars is observed.

According to calculations, increasing the capacity of the port elevator $H$ to 25 thousand tons reduces the generalized logistics costs $B$ from $12.6 \%$ for $D=30$ wagons/day to $9.1 \%$ under the condition $D=110$ wagons/day. The determined change $B$ is explained by the redistribution of freight flows according to transport schemes of their movement. In the case of ensuring the productivity of the grain terminal within $D=30-50$ wagons/day increase in the capacity of the port elevator $H$ leads to a decrease in grain traffic, provided the possibility of pre-accumulation and a corresponding increase in consolidated cargo flows. The availability of sufficient capacity for direct storage of goods in the transport node allows in the initial conditions to move through the port elevator from 47 to $53 \%$ of grain.

Thus, the development of trade relations based on economic integration between individual countries and the improvement of integration processes contribute to increasing the volume of export and transit cargo flows, and, accordingly, complicate the tasks of transport and customs and logistics services. Therefore, an important characteristic for transport hubs is compliance with the terms of accumulation and processing of these goods. Given the random nature of the supply of goods to transport hubs, it is important to form a rational infrastructure of transport systems. In this case, competitive servicing of foreign trade flows provided the optimal distribution of material resources becomes a priority of the customs and logistics system. The proposed methodology for the formation of the infrastructure of transport hubs provides an opportunity to identify ways to create promising, under conditions of intensive use of existing production facilities, customs and logistics systems. At the same time, the practical application of this methodology should take into account the peculiarities of customs and logistics services for export grain cargo flows. First of all, when performing calculations, one should take into account the fact that the export of grain cargo is seasonal and is performed mainly from August this year to March next year. In the inter-export period, some of the infrastructure elements (linear elevators, port railway stations) are involved in other technological processes. However, the rest of the port infrastructure (customs terminals, port elevators) is preceded by forced downtime. This situation should take into account the costs associated with the forced maintenance of a significant part of the specialized infrastructure of the transport hub.

In addition, it is known that grain cargoes are food products of plant origin that require appropriate storage conditions. But under such conditions of consolidation of grain cargo in vehicles (railway cars, barges, lanterns, etc.) there is a possibility of physical damage to the goods, which will also be reflected in its final value. However, these restrictions do not diminish the practical value of 
the proposed methodology for the formation of the infrastructure of transport hubs for servicing transit and export cargo flows.

\section{Conclusions}

In the process of conducting a study of the development of integration processes in the system of servicing export cargo flows, new results were obtained to improve the methodology for the formation of customs and logistics infrastructure in transport hubs. On the basis of the basic provisions of the theory of the system analysis regularities of interaction of separate structural elements of industrial formations of the international direction are defined. It is established that when increasing the accreditation capacity of the customs terminal from $M=5$ thousand tons to $M=30$ thousand tons, the generalized logistics costs $B$ decrease from $4.97 \%$ under the condition of daily productivity of ship loading mechanisms $Z=1000$ tons/day to $7.02 \%$ for the specified productivity indicator $Z=5000$ tons/day. The peculiarity of the results is that they take into account the impact of alternative methods of consolidation and storage of goods.

At the same time, the influencing factors take into account the peculiarities of the implementation of the necessary technological processes by different modes of transport. The obtained result of the reduction of the generalized logistics cost in the maintenance of grain cargo flows in transport hubs takes into account slightly reduced tariffs of customs terminals compared to port elevators, as well as increasing the intensity of railway cars and, consequently, reducing the total number of technological operations. It is taking into account the impact of the peculiarities of the functioning of different modes of transport allows to improve the methodology of forming the infrastructure of transport hubs.

Using the method of simulation modeling of the development of integration processes, integrated indicators of quality transport service are calculated on the example of grain cargo flows. It is determined that the increase in the productivity of ship loading mechanisms has a positive effect on the reduction of generalized logistics costs. Thus, the increase of this indicator from $Z=1000$ thousand tons/day to $Z=5000$ thousand tons/day reduces the numerical value of costs $B$ from $6.81 \%$ for the available capacity of the customs terminal $M=5$ thousand tons to $8.82 \%$ for $M=30$ thousand tons. Distinctive features of this indicator are that along with ship loading mechanisms that work on the direct option, loading the ship with grain cargo is performed by stationary equipment from port elevators and other means of transport. In this case, the customs and logistics infrastructure of the transport hub ensures the reliability of the contractual obligations for the timely service of the export consignment.

The study can be useful to improve the efficiency of customs and logistics services for foreign trade flows in international production structures. But when conducting multivariate calculations, in addition to the impact of resource provision for foreign trade, the peculiarities of servicing grain cargo flows by different modes of transport, seasonality of transportation and characteristics of cargo-forming and cargo-absorbing arrays must be taken into account.

\section{References}

1. Kulbovskyi, I., Bakalinsky, O., Sorochynska, O., Kharuta, V., Holub, H., Skok, P. (2019). Implementation of innovative technology for evaluating high-speed rail passenger transportation. EUREKA: Physics and Engineering, 6, 63-72. doi: http://doi.org/ 10.21303/2461-4262.2019.001006

2. Crainic, T. G., Perboli, G., Rosano, M. (2018). Simulation of intermodal freight transportation systems: a taxonomy. European Journal of Operational Research, 270 (2), 401-418. doi: http:// doi.org/10.1016/j.ejor.2017.11.061

3. Danchuk, V., Bakulich, O., Svatko, V. (2019). Identifying optimal location and necessary quantity of warehouses in logistic system using a radiation therapy method. Transport, 34 (3), 175-186. doi: http://doi.org/10.3846/transport.2019.8546

4. Taji, T., Tanigawa, S., Kamiyama, N., Katoh, N., Takizawa, A. (2008). Finding an Optimal Location of Line Facility using Evolutionary Algorithm and Integer Program. Journal of Computational Science and Technology, 2 (3), 362-370. doi: http:// doi.org/10.1299/jcst.2.362

5. Prokudin, G., Remekh, K., Maidanyk, K. (2017). The efficiency of the runsystem application in international freight transportation. Politechnika Rzeszozoska, 10, 79-86.

6. Shin, S., Roh, H.-S., Hur, S. (2019). Characteristics Analysis of Freight Mode Choice Model According to the Introduction of a New Freight Transport System. Sustainability, 11 (4), 1209 doi: http://doi.org/10.3390/su11041209

7. Sonmez, A. D., Lim, G. J. (2012). A decomposition approach for facility location and relocation problem with uncertain number of future facilities. European Journal of Operational Research, 218 (2), 327-338. doi: http://doi.org/10.1016/j.ejor.2011.10.028

8. Vorkut, T., Volynets, L., Bilonog, O., Sopotsko, O., Levchenko, I. (2019). The model to optimize deliveries of perishable food products in supply chains. Eastern-European Journal of Enterprise Technologies, 5 (3 (101)), 43-50. doi: http://doi.org/ 10.15587/1729-4061.2019.177903

9. Beloglazov, A., Banerjee, D., Hartman, A., Buyya, R. (2014) Improving Productivity in Design and Development of Information Technology (IT) Service Delivery Simulation Models. Journal of Service Research, 18 (1), 75-89. doi: http://doi.org/ $10.1177 / 1094670514541002$

10. Apfelstädt, A., Dashkovskiy, S., Nieberding, B. (2016). Modeling, Optimization and Solving Strategies for Matching Problems in Cooperative Full Truckload Networks. IFAC-PapersOnLine, 49 (2), 18-23. doi: http://doi.org/10.1016/j.ifacol.2016.03.004

11. Ritzinger, U., Puchinger, J., Hartl, R. F. (2015). A survey on dynamic and stochastic vehicle routing problems. International Journal of Production Research, 54 (1), 215-231. doi: http:// doi.org/10.1080/00207543.2015.1043403

Oleksandr Gryshchuk, PhD, Professor, Department of Tourism, National Transport University, Kyiv, Ukraine, ORCID: https://orcid.org/ 0000-0003-2993-5566

$\triangle$ Anatoliy Petryk, PhD, Associate Professor, Department of International Transport and Customs Control, National Transport University, Kyiv, Ukraine, e-mail: anv.petruk@gmail.com, ORCID: http:// orcid.org/0000-0001-7996-5814

Yaroslav Yerko, Postgraduate Student, Department of International Transport and Customs Control, National Transport University, Kyiv, Ukraine, ORCID: http://orcid.org/0000-0002-6759-9578

$\triangle$ Corresponding author 